\title{
Tribological Properties of the Oxide Coatings Produced onto 6061-T6 Aluminum Alloy in the Hard Anodizing Process
}

\author{
Przemysław Kwolek, Krzysztof Krupa, Andrzej Obłój, Paweł Kocurek, Małgorzata Wierzbińska, and Jan Sieniawski
}

(Submitted November 23, 2017; in revised form April 21, 2018; published online May 25, 2018)

\begin{abstract}
The aim of this work was to establish the influence of the thickness of the anodic coatings on their mechanical properties and to understand the relation between their hardness and the abrasion resistance. The coatings were produced in the hard anodizing process onto the 6061-T6 aluminum alloy. Their thickness was in the range between 19 and $43 \mu \mathrm{m}$. The abrasion resistance was determined by using Taber abrasion test. The weight losses of the coatings obtained were in the range between 15 and $11 \mathrm{mg}$ and decreased with their increasing thickness. It has been shown that the hardness measured on the cross sections of the coatings did not correspond to their abrasion resistance. Thus, the new approach has been proposed. The hardness of the coatings was estimated on the basis of the results of the scratch test performed at the constant load. The results obtained correspond to the abrasion resistance of the coatings.
\end{abstract}

Keywords aluminum alloy, abrasion resistance, hard anodizing, scratch test, Taber abrasion test

\section{Introduction}

Anodic coatings are produced onto the surface of various components, made of aluminum alloys, in order to enhance their surface properties. The well-known classification of the anodic coatings is given in the MIL-A-8625F military standard, where hard anodic coatings belong to type III (Ref 1). The anodic coatings are formed in the electrolytic process. Thus, their thickness should be proportional to the electrical charge passing the electrolytic cell. However, the kinetics of the formation of the coating depends also on the rate of its dissolution in the acidic electrolyte. The rate of dissolution of the anodic coating is dependent on the chemical composition of the electrolyte and its temperature. The characteristic features of the hard anodizing are low temperature of the bath (around $273 \mathrm{~K}$ ) and high current density (Ref 2, 3). The former ensures that the rate of dissolution of the coating is low. It is frequently observed that the thickness of the hard coatings depends linearly on the time of anodizing $(\mathrm{Eq} \mathrm{1)}$ :

\footnotetext{
Przemysław Kwolek, Pawel Kocurek, and Malgorzata Wierzbińska, Department of Materials Science, Faculty of Mechanical Engineering and Aeronautics, Rzeszow University of Technology, Rzeszow, Poland; Krzysztof Krupa and Andrzej Obłój, Research and Development Laboratory for Aerospace Materials, Rzeszow University of Technology, Rzeszow, Poland; and and Jan Sieniawski, Department of Materials Science, Faculty of Mechanical Engineering and Aeronautics, Rzeszow University of Technology, Rzeszow, Poland; and Research and Development Laboratory for Aerospace Materials, Rzeszow University of Technology, Rzeszow, Poland. Contact e-mail: pkwolek@prz.edu.pl.
}

$d=1.24 \cdot t$

where $d$ stands for the coating thickness in $\mu \mathrm{m}$ and $t$ is the anodizing time in minutes. The equation was calculated for the Alumilite 225/226 hard coating process from the data presented in Ref 2.

The coatings produced in the hard anodizing process are usually thick, hard and abrasion-resistant. According to the MIL-A-8625F standard, their typical thickness is between 12.7 and $114 \mu \mathrm{m}$ (Ref 1). The standard also defines the methods of characterization of the abrasion resistance, corrosion resistance, thickness and mass of the coatings. The only method allowed for the determination of their abrasion resistance is by using Taber Abraser (Ref 1).

The abrasion resistance of the anodic coatings is strongly dependent on the anodizing conditions and the chemical composition of the alloy. The most wear-resistant coatings are those produced on the pure aluminum; however, satisfactory results are also easy to achieve for $\mathrm{Al}-\mathrm{Mg}-\mathrm{Si}$ and $\mathrm{Al}-\mathrm{Zn}-\mathrm{Mg}$ wrought alloys. In general, the increase in the concentration of the alloying elements causes the decrease in the abrasion resistance. It is especially true for the copper- and silicon-rich alloys. These two alloying elements deteriorate also the hardness and corrosion resistance of the anodic coatings (Ref 2-5). Copper forms the intermetallic phases, with aluminum and other alloying elements, such as $\mathrm{CuAl}_{2}, \mathrm{Al}_{2} \mathrm{CuMg}$ and $\mathrm{AlCuNi}$. During the process of formation of anodic coating, they dissolve in the anodizing bath instead of being subject to oxidation. Silicon is only slightly oxidated during anodizing. Its presence in the alloy in the form of eutectic crystals causes the significant inhomogeneity of the thickness of the anodic coating (Ref 6, 7).

The 6061 aluminum alloy is commonly applied, e.g., in the aircraft industry, due to its good mechanical properties after precipitation hardening. Its major alloying elements are magnesium (0.8-1.2 wt.\%) and silicon (0.4-0.8 wt.\%). Thus, the anodic coatings of good quality can be easily produced onto this alloy. Their properties such as the corrosion, erosion and abrasion resistance as well as hardness and fatigue life have been already determined (Ref 2, 8-12). 
The abrasion resistance is usually tested by using different methods such as jet abrasion and abrasive wheel test (Ref 1, 2, 12). Pin-on-disk as well as ball-on-disk methods are also frequently used to quantify the tribological properties of the coatings (Ref 8,13$)$. In this work, Taber Abraser was applied according to the MIL-A-8625F standard. Since it is impossible to compare the results obtained by using different methods (e.g., pin-on-disk and Taber abrasion test), only the results from the latter are discussed in this work.

Taber abrasion test is to be performed according to the ASTM D4060 standard (Ref 14). The flat specimen in the form of the square $\left(10 \times 10 \mathrm{~cm}^{2}\right)$ or circle $(10 \mathrm{~cm}$ diameter $)$ is rotated (60 rpm) and abraded with the two CS-17 abrading wheels composed of a resilient binder and $\mathrm{Al}_{2} \mathrm{O}_{3}$ or $\mathrm{SiC}$ abrasive particles. The load applied for each wheel is $9.81 \mathrm{~N}$. The surface of the wheels must be frequently renewed, using the emery paper, during the test. The test is finished after 10,000 of rotations of the specimen. The weight loss is then reported. The weight loss for the coatings produced onto the 6061 aluminum alloy is in the wide range, between 7 and $25 \mathrm{mg}$ (Ref 4).

The hardness of the anodic coatings is usually measured on their cross sections. It strongly depends on the chemical composition of the alloy. In the case of the 6061 alloy, the hardness is between 420 and $490 \mathrm{HV}$ and does not depend on the thickness of the coating ( Ref 2, 11, 12).

In this work, the anodic coatings were produced onto 6061 alloy in the standard, d.c. process. The anodizing process was not optimized for the best abrasion resistance or the hardness of the coating. The aim of the work was to understand the relations between the mechanical properties of the coatings such as the abrasion resistance determined by using Taber Abraser, hardness and adhesion to the substrate. The influence of the thickness of the coating on these properties was also determined.

\section{Experimental Procedure}

The experiments were performed with the 6061-T6 aluminum alloy specimens. Their chemical composition is given in Table 1.

The $100 \times 100 \times 2 \mathrm{~mm}^{3}$ specimens were cut from the sheet metal. Then, they were degreased and pickled in the alkaline solution containing $100 \mathrm{~g} \mathrm{dm}^{-3} \mathrm{NaOH}$ (2 min at $290 \mathrm{~K}$ ), rinsed in deionized water, etched in the nitric acid aqueous solution $(50 \% \mathrm{vol}, 2 \mathrm{~min}$ at $290 \mathrm{~K}$ ) and rinsed. The anodic coatings were produced in the sulfuric acid aqueous solution $\left(158 \mathrm{~g} \mathrm{dm}^{-3}\right)$ at $273 \mathrm{~K}$, at the constant current density $2.5 \mathrm{~A} \mathrm{dm}^{-2}$ by using the FlexKraft power supplier (Kraft Powercon, Sweden). The aforementioned parameters are virtually the same as for the well-known M.H.C (Martin Hard Coat) process (Ref 2). The bath was vigorously agitated with the compressed air. The time of anodizing was equal to $7,30,45$ and $60 \mathrm{~min}$ in order that different thicknesses of the coatings was achieved. The anodized specimens were rinsed in the deionized water and dried in the air. One of them was subsequently annealed in the laboratory oven in the atmosphere of air at $373 \mathrm{~K}$ for $1 \mathrm{~h}$.

The analysis of the topography of the surface of the coatings was performed by using the profilometer Mahr PS2 with diamond stylus (radius $2 \mu \mathrm{m}$ ). The evaluation length was equal to $5.6 \mathrm{~mm}$, the five consecutive cutoff lengths $0.8 \mathrm{~mm}$ were applied. The microstructure of the coatings was evaluated by using the scanning electron microscope (SEM) Hitachi S$3400 \mathrm{~N}$ with the EDS system. The thickness of the anodic coatings was determined by the microscopic examination of their cross sections. The eddy-current method (Dualscope FMP100, Fischer) was also applied.

Taber Abraser was employed to determine the abrasion resistance of the anodic coatings, according to the ASTM D4060 standard (Ref 14). The coatings, rotated at the speed equal to $60 \mathrm{rpm}$, were abraded with the CS-17 abrasive wheels under $9.81 \mathrm{~N}$ load. The abrasion resistance of the coatings was quantified as their weight loss after 10,000 revolutions. The weight loss was determined after every 500 revolutions with the aim of evaluating the kinetics of the wear. The abrasive wheels were refaced every 500 revolutions to renew their surface.

The hardness was measured both on the surface of the coatings and their cross sections by using the Vickers hardness tester (CSM Instruments). For the former, the constant penetration depth of $4 \mu \mathrm{m}$ was applied. For the latter, the metallographic specimens were prepared. The measurements were taken at $50 \mathrm{mN}$ load in the center of the coatings.

Scratch tests were performed by using the scratch tester (CSM Instruments) equipped with the Rockwell-type diamond stylus. First, the tests were conducted at the constant load $10 \mathrm{~N}$; at the $5 \mathrm{~mm}$ distance, the speed of the stylus was equal to $10 \mathrm{~mm} \mathrm{~min}^{-1}$. Subsequently, the increasing load was applied from 0 to $50 \mathrm{~N}$ with the speed equal to $5 \mathrm{~N} \mathrm{~s}^{-1}$ at the $5 \mathrm{~mm}$ distance.

\section{Results and Discussion}

\subsection{Microstructure, Thickness and Roughness of the Coatings}

The microstructural components of the precipitation-hardened substrate are: $\alpha-\mathrm{Al}$ solid solution and the particles of the intermetallic phases. Since iron is one of the most common impurities in aluminum, the particles of the iron-rich intermetallic phases are always present in the matrix. They dissolve in the bath during anodizing. As a result, the macropores in the coating are observed (Fig. 1). The characteristic feature of the precipitation-hardened Al-Mg-Si alloy is fine particles of the $\beta$ $\mathrm{Mg}_{2} \mathrm{Si}$ phase dispersed in the matrix. They precipitate during

Table 1 The chemical composition of the 6061 aluminum alloy

The content of the elements, wt. $\%$

\begin{tabular}{lccccccccc}
\hline Al & Mg & Si & Fe & Cu & Zn & Ti & Mn & Cr & Other \\
\hline 96.00 & 1.12 & 0.63 & 0.55 & 0.21 & 0.23 & 0.11 & 0.09 & 0.08 & 0.08 \\
\hline
\end{tabular}




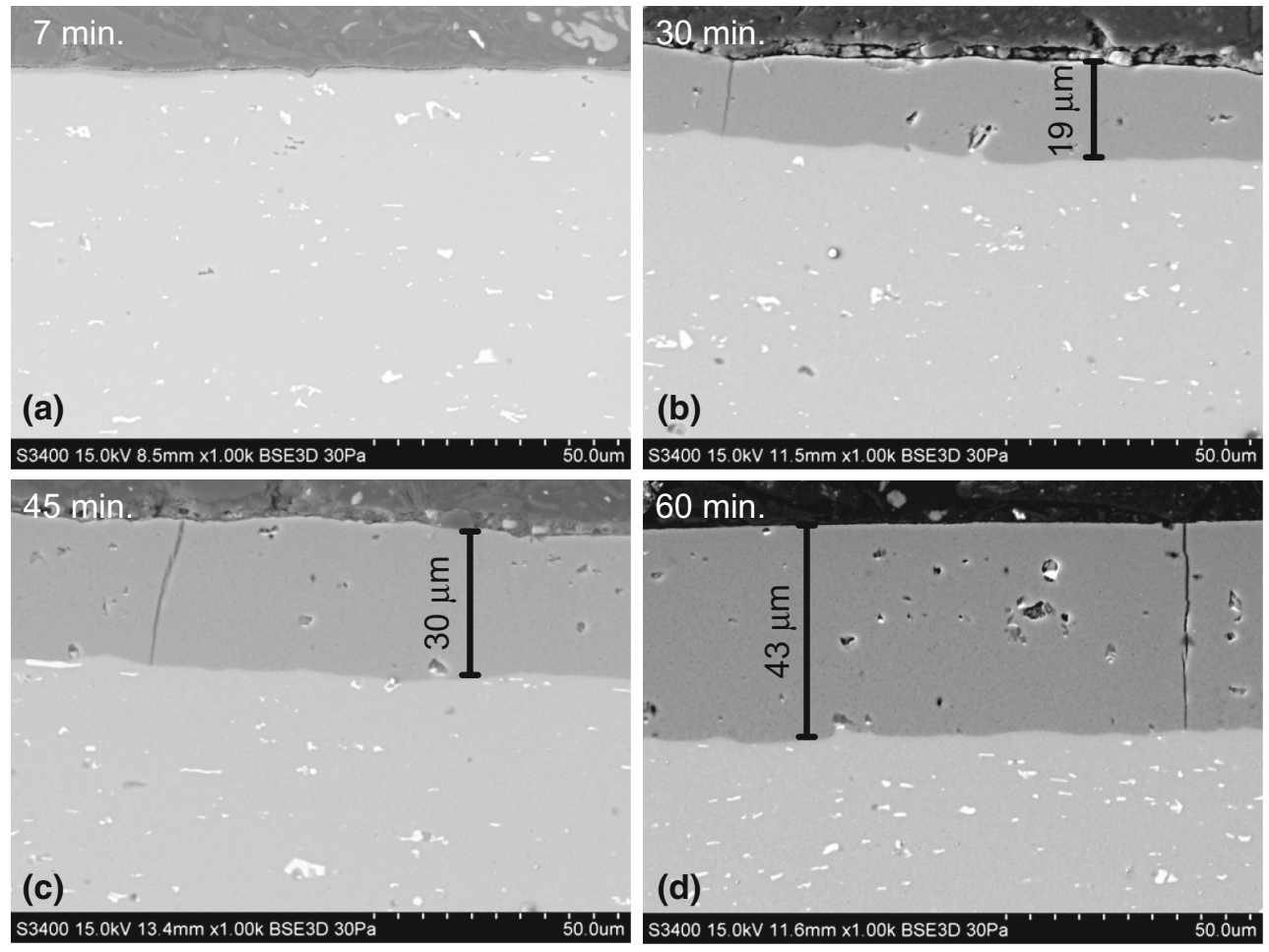

Fig. 1 The microstructures of the cross sections of the coatings obtained with different time of anodizing

the artificial aging and increase the hardness of the alloy. In Fig. 1, they are not visible due to applied magnification. Since these particles easily undergo oxidation during the anodizing process, their presence in the alloy is not detrimental for the properties of the coatings (Ref 6, 7).

The chemical composition of the coatings produced was determined by using energy-dispersive x-ray spectroscopy (EDS). The following results were obtained: oxygen (5159 at.\%), aluminum (39-49 at.\%), sulfur (1-2 at.\%).

The microscopic examination of the cross sections of the coatings, obtained at different time of anodizing, was performed. The coating obtained after $7 \mathrm{~min}$ of anodizing is very thin and hardly visible in Fig. 1(a). The examination of the thicker coatings indicated their uniform thickness (Fig. 1b-d). In the microphotographs, the cracks in the coatings are visible (Fig. 1b-d). There are two main reasons for cracking of the anodic coatings. The first one is the thermal stress caused by the significant difference in the thermal expansion coefficients of the anodic coating and the metallic substrate. The cracks could appear when the coatings were withdrawn from the cold bath $(273 \mathrm{~K})$ and rinsed in the tank filled with water at the room temperature. The other one is the mechanical stress. The cracks could arise when the metallographic cross sections were prepared (Ref 2).

The thickness of the coatings was determined by using the eddy-current and microscopic technique. The metallographic specimens were prepared and examined by using the scanning electron microscope. The values obtained were ranged between 19 and $45 \mu \mathrm{m}$. Very good correlation was achieved between the thickness determined by destructive and nondestructive technique (Fig. 2a). The thickness of the coating obtained after $t=7 \mathrm{~min}$ is equal to $1 \mu \mathrm{m}$, and it increases linearly with time, achieving $43 \mu \mathrm{m}$ after $60 \mathrm{~min}$ (Fig. 2b).
The characterization of the topography of the surface of the coatings obtained is necessary for understanding their tribological properties. The roughness of the surface was evaluated by using two amplitude parameters $R_{\mathrm{a}}$ and $R_{\mathrm{z}}$ (Fig. 3). The former is defined as the average deviation of the surface profile from the mean line over a certain length. The latter accounts for the difference in height between the average five highest peaks and lowest valleys. It is more sensitive to the occasional high peaks or deep valleys than $R_{\mathrm{a}}(\operatorname{Ref} 15)$. First of all, the values of the roughness parameters were determined for the non-anodized specimen. It was only degreased and etched at the same conditions as the anodized specimens. The roughness parameters were determined in the two, mutually perpendicular directions $X$ and $Y$. The first one was perpendicular to the direction of rolling, the other one-parallel. It has been observed that the values of $R_{\mathrm{a}}$ and $R_{\mathrm{z}}$ determined in the $X$ direction are lower when compared to those obtained for the $Y$ direction. The roughness of the rolled sheet depends on the roughness of the rolling mills. Therefore, there is no rule whether the roughness of the sheet is higher in the direction perpendicular or parallel in relation to the direction of rolling.

It can be concluded that the roughness of the anodic coatings is significantly higher when compared to the uncoated, pre-treated specimen (degreased and etched). Along the $X$ direction, the values of the $R_{\mathrm{a}}$ and $R_{\mathrm{z}}$ virtually do not depend on the thickness of the coatings. For the $Y$ direction, both $R_{\mathrm{a}}$ and $R_{\mathrm{z}}$ are higher for each coating. It is due to their higher values for the uncoated specimen. In addition, for the coating with thickness of $43 \mu \mathrm{m}$, the highest values of both roughness parameters were observed. The increase in the roughness of the anodic coating with its thickness has already been reported in the literature. The roughness of the coating depends on the chemical composition of the bath. For instance, coatings 

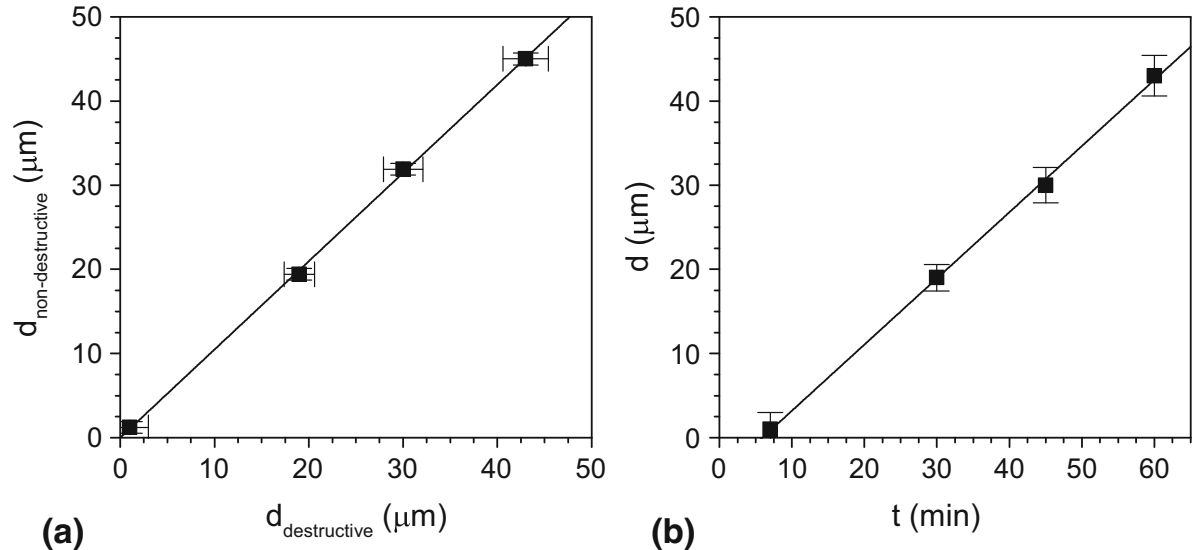

Fig. 2 The comparison between the thickness of the anodic coatings determined with the nondestructive and destructive method (a), the thickness of the coating as the function of the time of anodizing (b); error bars represent the standard deviations of the average values of the thickness of the coatings
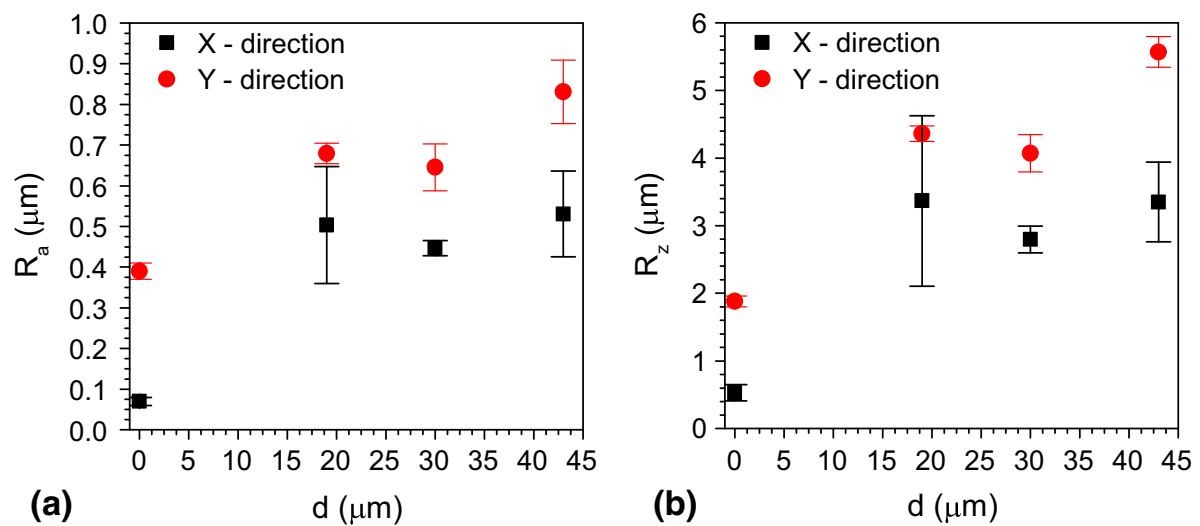

Fig. 3 Roughness parameters $R_{\mathrm{a}}$ (a) and $R_{\mathrm{z}}$ (b) of the coatings as the function of their thickness, measured in the directions perpendicular $X$ and parallel $Y$ to the direction of rolling); data points for $d=0 \mu \mathrm{m}$ indicate the uncoated specimen

obtained in the oxalic acid aqueous solutions are smoother when compared to those obtained in the sulfuric acid aqueous solutions. Furthermore, the higher the anodizing temperature and the current density, the higher the roughness of the anodic coatings (Ref 16). It also depends on the pre-treatment process. In this work, the specimens were degreased and etched in the strongly alkaline solution. It roughened their surface and influenced the final roughness of the coatings.

\subsection{Abrasion Resistance}

The weight loss obtained for the coatings with different thickness is presented in Fig. 4(a). It is possible to see that it increases linearly with the number of the revolutions. Such a linear dependence of the weight loss with the number of revolutions can be only achieved if the abrasive wheels are frequently refaced. Otherwise, significant deviation from the linearity occurs and the weight loss values after 10,000 of revolutions are underestimated. It has been observed that when the surface of the abrasive wheels was not renewed, the weight loss after 10,000 of revolutions was equal to approximately $70 \%$ of the true value (data not shown).

The abrasion resistance is quantitatively determined in this method as the weight loss of the specimen after 10,000 revolutions. The dependency of these values on the thickness of the coatings is summarized in Fig. 4(b). The error bars represent the standard deviation of the average weight loss calculated for 3 specimens. It can be concluded that the higher the thickness of the coating, the better its abrasion resistance. The weight loss decreases linearly with the increasing thickness of the coating. According to the MIL-A-8625F standard, the weight loss for the coatings produced on such an alloy should be lower than $1.5 \mathrm{mg}$ per 1000 revolutions (Ref 1).

The abrasion resistance of the anodic coatings (and other materials in general) depends on two factors. The first one, which is exclusively related to the material itself, is its hardness. Obviously, the harder the protective coating is, the better its abrasion resistance. The other one is related to the roughness of the surface of the coating. When it is high, one should expect the increased wear of the coating. However, in case of the following work, the best abrasion resistance has been achieved for the thickest and concurrently the roughest coating. Therefore, the above coating is presumably the hardest of all the produced. Surprisingly, the results of the hardness tests, performed onto the cross sections of the coatings, did not support this hypothesis. It has been known that the hardness measured on the cross section of the coating does not necessarily correspond with the abrasion resistance (Ref 2). Thus, the alternative methodology for the determination of the hardness of the coating has been proposed (vide infra). The 

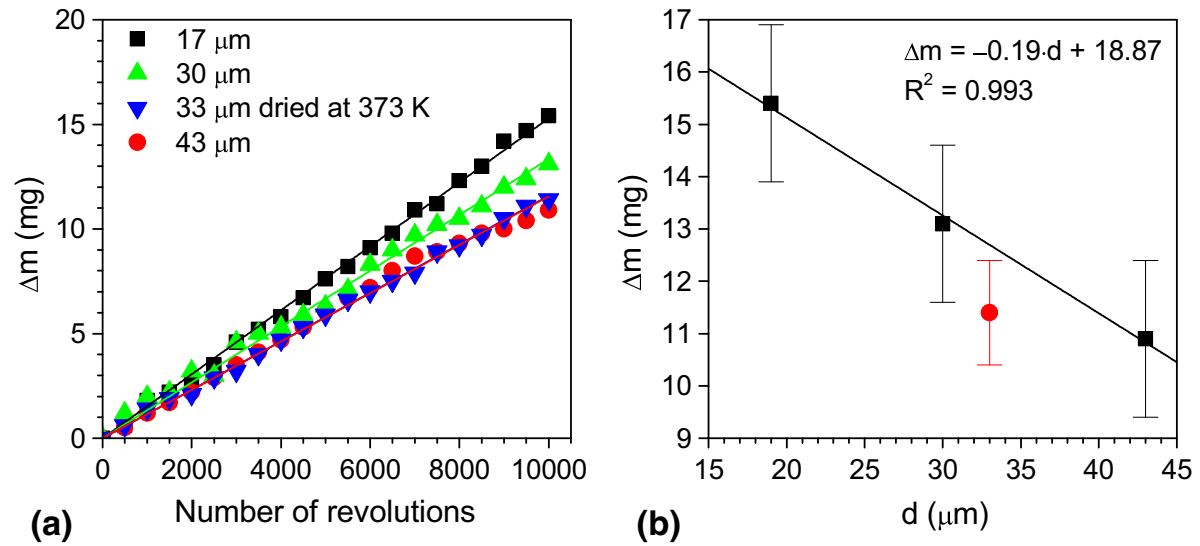

Fig. 4 The weight loss of the coatings as the function of the number of revolutions (a), the weight loss values after 10,000 revolutions as the function of the thickness of the coatings (b); the point represented with circle indicates the coating annealed at $373 \mathrm{~K}$

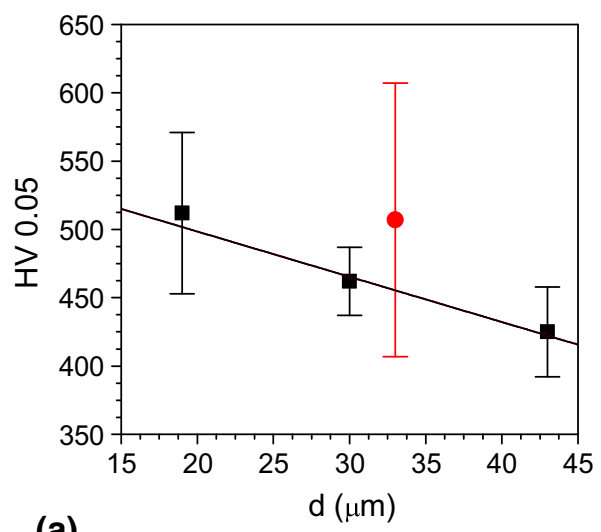

(a)

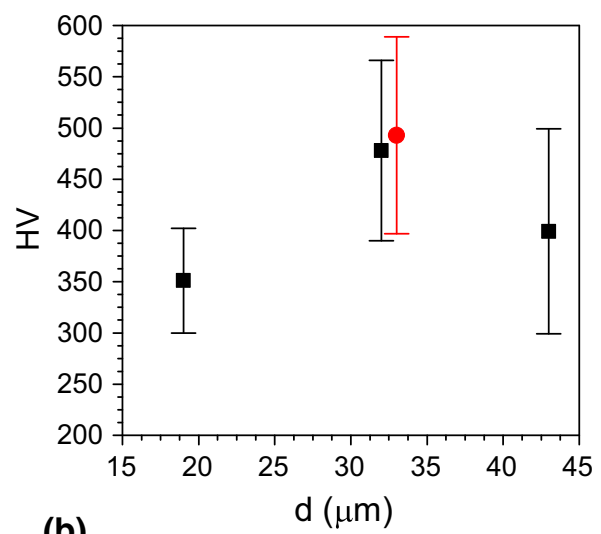

(b)

Fig. 5 The hardness of the coatings as the function of their thickness: measured on their cross sections at the constant load (a), measured on the surface of the coatings at a load necessary to obtain the penetration depth equal to $4 \mu \mathrm{m}$ (b); the point represented with circle indicates the coating annealed at $373 \mathrm{~K}$

results obtained support the hypothesis that the best abrasion resistance was obtained for the hardest coating.

On the one hand, good abrasion resistance is obtained for the compact coatings. On the other hand, prolonged time, necessary for obtaining the thickest coating, should favor its dissolution and lead to the increased porosity. It can be concluded that at the applied conditions of anodizing, the kinetics of dissolution is so low that no significant increase in the porosity of the coating has been observed after 60 min of anodizing.

It has been shown that the annealing of the coating at $373 \mathrm{~K}$ does not deteriorate the abrasion resistance, when compared to the coating with the same thickness, that was not annealed. The heat treatment of the coating is necessary, if it had been impregnated or painted. For certain applications, e.g., in the aircraft industry, the abrasion resistance of the hard anodic coating is insufficient. However, it can be improved by the decrease in its friction coefficient. Therefore, hard anodic coatings are sometimes impregnated in the water suspensions of the particles of polytetrafluoroethylene (PTFE) or molybdenum disulfide (Ref 17-20). Subsequently, the coating is annealed. The annealing temperature should not exceed the aging temperature of the alloy. Otherwise, the hardness of the metallic substrate will decrease.
It should be noted here that the coating before annealing should be carefully dried. If this is not the case, the chemical sealing of the coating will occur. When the temperature is above $353 \mathrm{~K}$, the hydration of $\mathrm{Al}_{2} \mathrm{O}_{3}$ occurs and $\mathrm{Al}_{2} \mathrm{O}_{3} \cdot \mathrm{H}_{2} \mathrm{O}$ is formed. This process deteriorates the wear resistance of the coatings; thus, it is not used for the hard anodic coatings. However, the chemical sealing is usually applied for the anodic coatings produced for anti-corrosive purpose. They are usually sealed in the deionized water $(368 \mathrm{~K})$, steam or aqueous solutions of salts of heavy metals such as sodium dichromate, nickel and cobalt acetate (Ref 21).

\subsection{Hardness of the Coatings}

It is assumed that the high abrasion resistance of the anodic coatings arises due to their high hardness. It is usually recommended to measure the hardness on the cross section of the coating in order to avoid the influence of the relatively soft substrate (Ref 2). In this work, the hardness, measured on the cross sections of the coatings, decreases slightly with their increasing thickness (Fig. 5a). The above fact contradicts their abrasion resistance. (The coating with the lowest hardness exhibits the best abrasion resistance.) The explanation for such a discrepancy is as follows. Both the hardness and the abrasion 

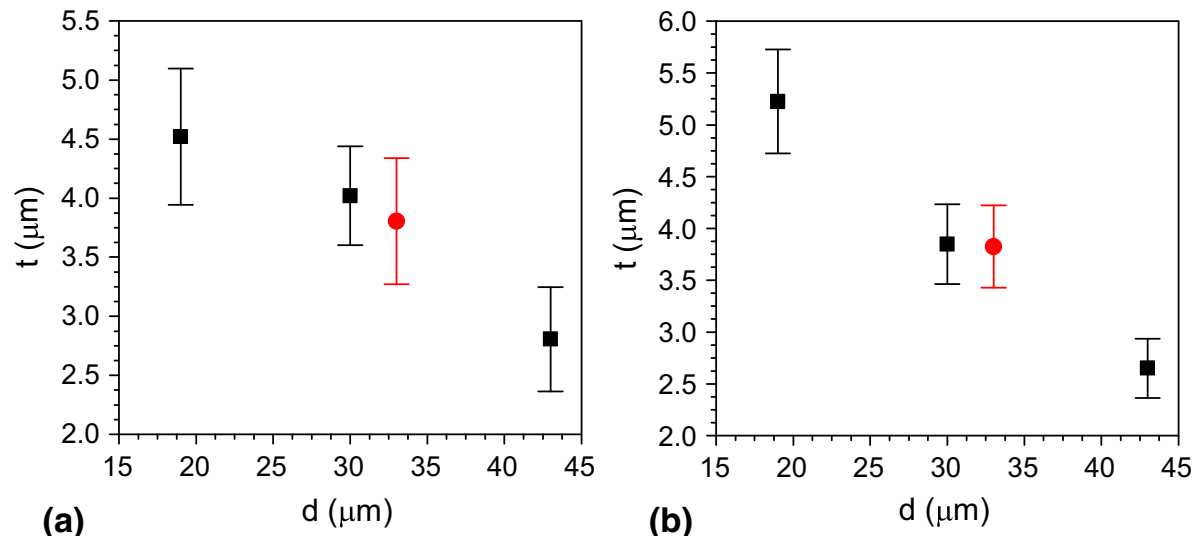

Fig. 6 The depth of penetration of the coatings, obtained during the scratch test at the constant load, as the function of their thickness measured in the directions perpendicular (a) and parallel (b) to the direction of rolling; the point represented with circle indicates the coating annealed at $373 \mathrm{~K}$
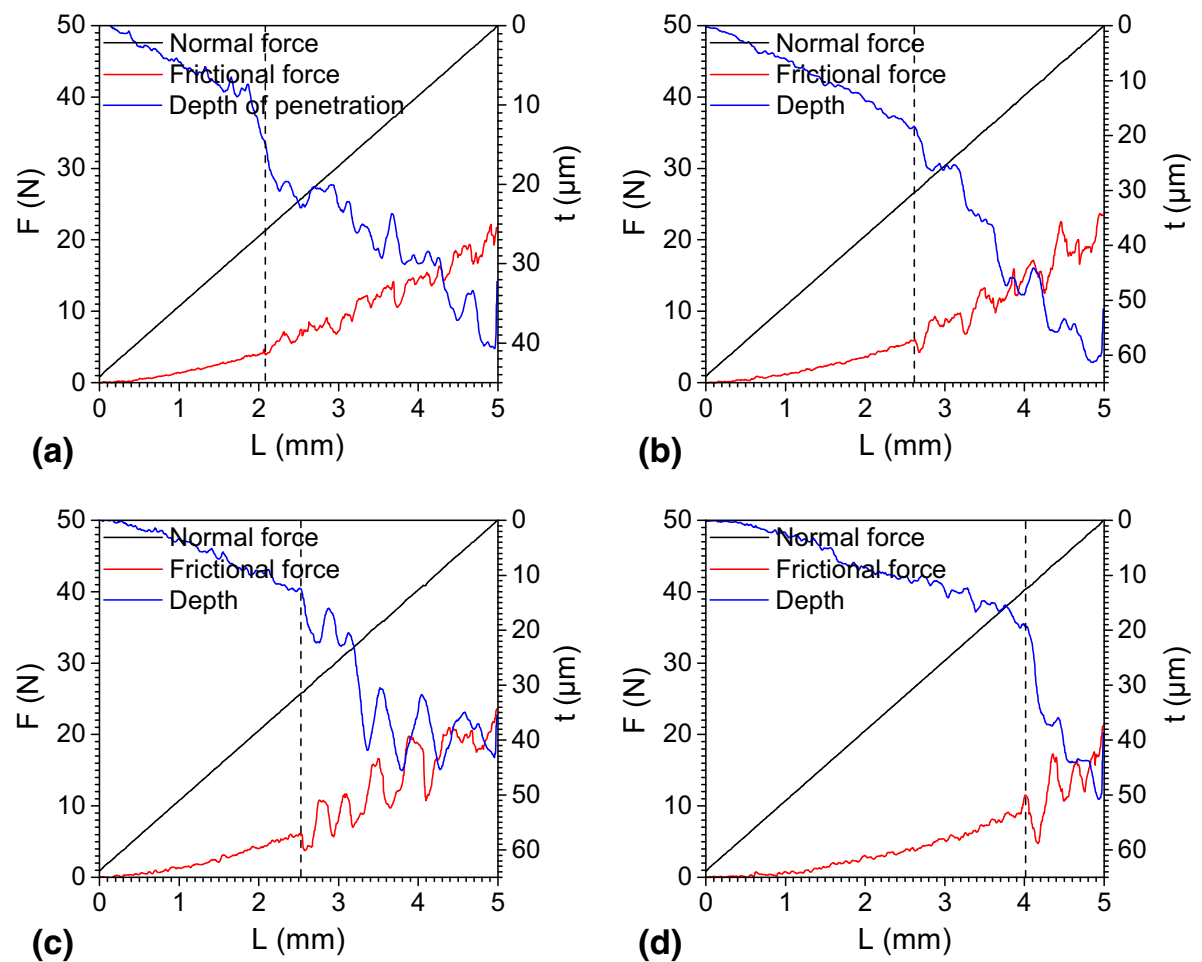

Fig. 7 The normal force, frictional force and penetration depth as the function of the distance of the stylus during the scratch test (direction perpendicular to the direction of rolling) for coating thickness: (a) $19 \mu \mathrm{m}$, (b) $30 \mu \mathrm{m}$, (c) $33 \mu \mathrm{m}$, annealed, (d) $43 \mu \mathrm{m}$

resistance are related to the stress state within the coating. The internal stress should be compressive in the direction perpendicular to the surface of the coating, to ensure its high hardness and good wear resistance. However, the hardness measured on the cross section takes into account the value of the stress within the coating, in the direction parallel to its surface. It influences the abrasion resistance of the coatings to the lesser extent, when compared to stress in the direction perpendicular to the surface. Therefore, the hardness measured onto the surface should better correlate with the abrasion resistance of the coating, in comparison with the hardness obtained at the cross section of the coatings.

The hardness was measured on the surface of the coatings at the different values of the load, to achieve the same depth of penetration equal to $4 \mu \mathrm{m}$ for each coating. This outer part of the coating is abraded in Taber test. It has been observed that the hardness of the coatings does not decrease with their increasing thickness (Fig. 5b). However, the expected correlation between the hardness and the abrasion resistance of the coating has not been confirmed, due to significant uncertainties of the hardness values. In general, the reliable determination of the hardness of the anodic coatings onto their surface can be problematic. On the one hand, the penetration of the coating should be shallow to avoid the influence of the soft substrate. On the other hand, it should be sufficiently deep due to significant roughness of the surface (Fig. 3).

Since the relation of the hardness of the coatings, measured on their surface, with the coating thickness was unclear, another approach has been proposed. The hardness of the anodic 
coatings was deduced from the results of the scratch test, performed at the constant load (Fig. 6a and b). The penetration depth measured should be proportional to the hardness of the coating. The advantage of this method, over the hardness measured on the cross section of the coating, is that it takes into account the stress state within the coating, in the direction perpendicular to the surface, which is responsible for its abrasion resistance. In addition, the roughness of the surface influences the result to a lesser extent, when compared to the hardness measured on the surface of the coating, since the

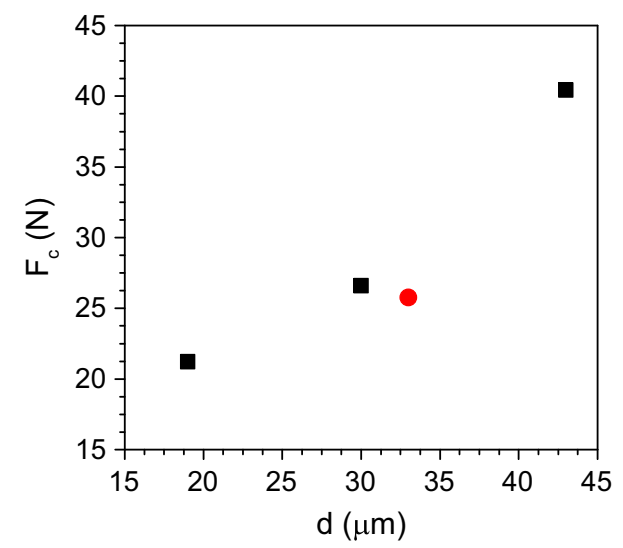

Fig. 8 The critical load as the function of the thickness of the coatings; the point represented with circle indicates the coating annealed at $373 \mathrm{~K}$ penetration depth can be averaged over the long distance of the scratch. It has been observed that the penetration depth decreases with the increasing thickness of the coating. Such a dependency occurs both, when the scratch was made in the directions perpendicular and parallel to the rolling direction. It means that the hardness of the coatings increases with their increasing thickness. This conclusion is consistent with the abrasion resistance of the coatings, i.e., the hardest coating is the most wear-resistant. It shows the advantage of this method over the standard hardness test.

\subsection{The Scratch Resistance of the Coatings}

The adhesion of the coatings to the substrate was evaluated by using the scratch test at the increasing load. Each coating was tested in both $X$ and $Y$ directions; however, no significant differences were observed. The critical load, $F_{c}$, was determined at the point where the oscillation in the frictional force occurred. It is related to the significant increase in the penetration depth. It can be observed that the penetration depth, achieved at the critical load, does not increase with the increasing thickness of the coatings. It is equal to $15 \mu \mathrm{m}$ for the coating with thickness of $19 \mu \mathrm{m}$ (Fig. 7a), $18 \mu \mathrm{m}$ for the coating with thickness of $33 \mu \mathrm{m}$ (Fig. $7 \mathrm{~b})$, slightly less $(14 \mu \mathrm{m})$ for the coating annealed (Fig. 7c) and $19 \mu \mathrm{m}$ for the thickest coating (Fig. 7d). Such a behavior is related to the mechanism of the failure of the coating. Nevertheless, the critical load increases with the increasing thickness of the coating (Fig. 8).

The critical load usually indicates that the coating loses its adhesion to the substrate. However, its physical meaning for the

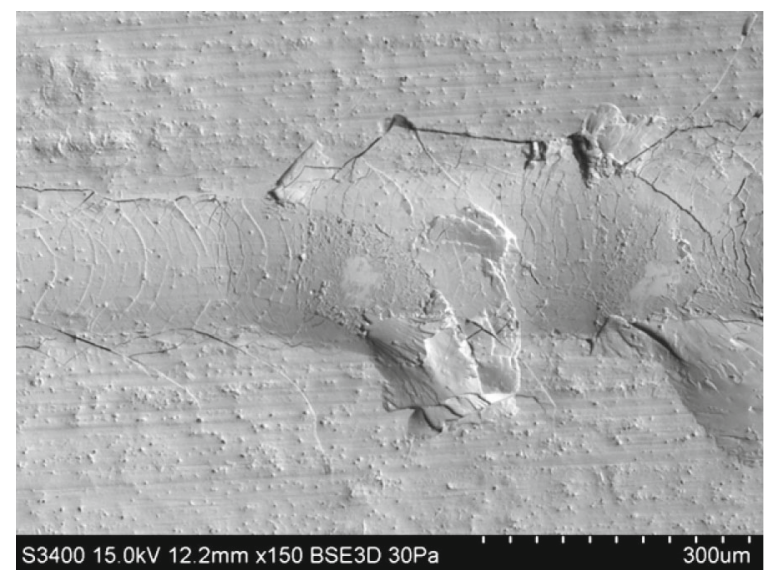

(a)

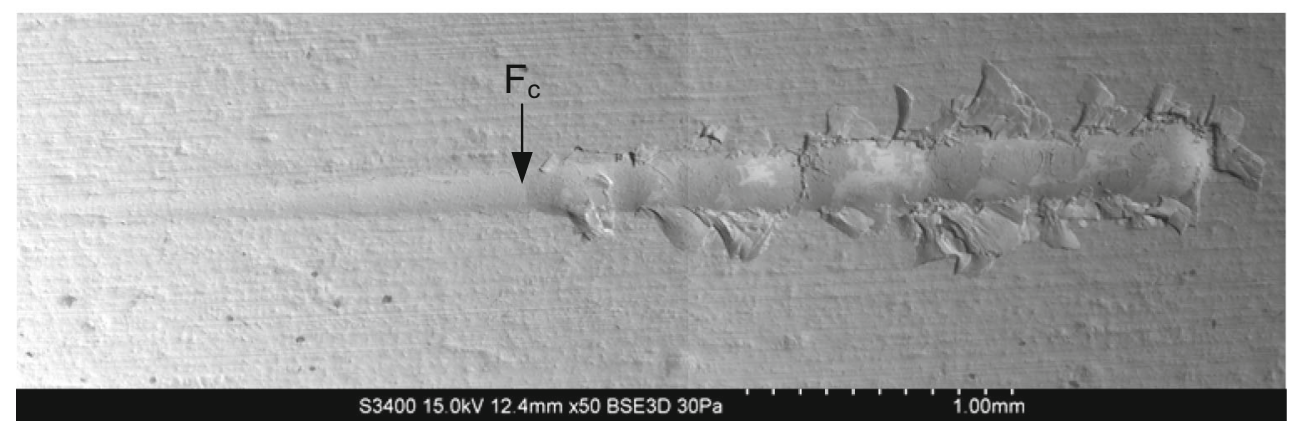

(b)

Fig. 9 The morphology of the scratch groove perpendicular to the rolling direction on the surface of the annealed coating, the thickness of $33 \mu \mathrm{m}$ 
scratch tests of anodized aluminum is different. Since the anodic coatings are the conversion coatings, their characteristic feature is the excellent adhesion to the substrate. Thus, usually no adhesion test is necessary for them (Ref 2). The diamond stylus penetrates the coating deeper with the increasing load. At its certain value, the cracking of the coating occurs. The cracks are transverse to the direction of the movement of the stylus, and the chipping of the coating is observed (Fig. 9a and b). Chipping of the coating becomes visible at the length of the scratch groove corresponding to the value of the critical load (Fig. 7). The stress necessary to achieve the adhesive failure of the coating is bigger when compared to the cohesive strength of the anodic coatings produced. Such a behavior usually occurs for the thick, hard coatings deposited onto a softer substrate. It also explains why the critical load occurs at the penetration depth much lower when compared to the thickness of the coating (Ref 22).

\section{Summary}

The new methodology for the determination of the hardness of the coatings has been proposed. The hardness is inversely proportional to the depth of penetration of the stylus during the scratch test performed at the constant load. Indisputably, this method has the following advantages. Firstly, the results obtained correspond to the abrasion resistance of the coating, contrary to the results of the hardness test obtained on the cross sections of the coatings. Secondly, it is less sensitive to the occasional changes in the hardness of the coatings due to their defects such as pores and cracks, when compared to the hardness measured on the surface of the coating. Thirdly, the proposed method can be applied on the rough coatings that should not be tested using the standard hardness test. To recapitulate, the proposed method can be used for the simple discrimination of the coatings produced, e.g., at various parameters. It is cheaper and less time-consuming when compared to Taber abrasion test.

To sum up, it has been shown that the abrasion resistance of the coatings produced increases with the increase in their thickness. Therefore, the best abrasion resistance was achieved for the thickest coating.

As far as the critical load values determined in the scratch test are concerned, they increase with the increasing thickness of the coatings. However, they correspond to the chipping within the coating, instead of its adhesive failure. The latter has not been observed during the scratch tests.

\section{Acknowledgments}

Project no. UOD-DEM-1-557/001, co-financed by the European Union under the European Regional Development Fund within the Innovative Economy Operational Program, is gratefully acknowledged. Przemysław Kwolek was supported by the Foundation for Polish Science within the START fellowship.

\section{Open Access}

This article is distributed under the terms of the Creative Commons Attribution 4.0 International License (http://creativecommons.org/ licenses/by/4.0/), which permits unrestricted use, distribution, and reproduction in any medium, provided you give appropriate credit to the original author(s) and the source, provide a link to the Creative Commons license, and indicate if changes were made.

\section{References}

1. Military Specification MIL-A-8625F, Anodic Coatings for Aluminum and Aluminum Alloys, Naval Air Warfare Center Aircraft Division Lakehurst, Lakehurs, NJ, 1993

2. P.G. Sheasby, R. Pinner, and S. Wernick, The Surface Treatment and Finishing of Aluminium and its Alloys, ASM International, Russell Township, 2001

3. M. Jozefowicz, Hard Coat Aluminum Anodizing, Met. Finish., 2005, 103, p 39-41

4. D.R. Gabe, Hard Anodizing-What do We Mean by Hard?, Met. Finish., 2002, 100, p 52-58

5. J. Runge and L. Chesterfield, The science of successfully anodizing die cast substrates, Alum. Int. Today, 2010, 22, p 30-36

6. L.E. Fratila-Apachitei, F.D. Tichelaar, G.E. Thompson, H. Terryn, P. Skeldon, J. Duszczyk, and L. Katgerman, A transmission electron microscopy study of hard anodic oxide layers on $\mathrm{AlSi}(\mathrm{Cu})$ alloys, Electrochim. Acta, 2004, 49, p 3169-3177

7. S. Bagdach (ed.), Poradnik galwanotechnika, Wydawnictwo Naukowo-Techniczne, Warszawa, 2002

8. J. Picas, A. Forn, and E. Rupérez, M Teresa Baile, E Martín, Hard Anodizing of Aluminium Matrix Composite A6061/( $\left(\mathrm{Al}_{2} \mathrm{O}_{3}\right)_{\mathrm{p}}$ for Wear and Corrosion Resistance Improvement, Plasma Process. Polym., 2007, 4, p S579-S583

9. M. Franco, T.H. Krishna, A.M. Pillai, A. Rajendra, and A.K. Sharma, A comparative study on the corrosion behaviour of hard anodic coatings on AA 6061 obtained using DC and pulsed DC power sources, Acta Metall. Sin. (English Lett), 2013, 26, p 647-656

10. Y. Huang, H. Shih, H. Huang, J. Daugherty, W. Shun, S. Ramanathan, C. Chang, and F. Mansfeld, Evaluation of the corrosion resistance of anodized aluminum 6061 using electrochemical impedance spectroscopy (EIS), J. Corros. Sci., 2008, 50, p 3569-3575

11. G. Sundararajan, Nitin P. Wasekar, and N. Ravi, The influence of the coating technique on the high cycle fatigue life of alumina coated $\mathrm{Al}$ 6061 alloy, Trans. Indian Inst. Met., 2010, 63, p 203-208

12. L.R. Krishna, A.S. Purnima, and G. Sundararajan, A comparative study of tribological behavior of microarc oxidation and hard-anodized coatings, Wear, 2006, 261, p 1095-1101

13. U. Malayoglu, K.C. Tekin, U. Malayoglu, and S. Shrestha, An Investigation into the Mechanical and Tribological Properties of Plasma Electrolytic Oxidation and Hard-Anodized Coatings on 6082 Aluminum Alloy, Mater. Sci. Eng., A, 2011, 528, p 7451-7460

14. ASTM Standard D4060-09, Standard Test Method for Abrasion Resistance of Organic Coatings by the Taber Abraser, ASTM International, West Conshohocken, PA, 2009

15. E.S. Gadelmawla, M.M. Koura, T.M.A. Maksoud, I.M. Elewa, and H.H. Soliman, Roughness Parameters, J. Mater. Process. Technol., 2002, 123, p 133-145

16. C. Steffani, Micro-finish hard anodized coatings on aluminum, In: Proceedings of 79th AESF annual technical conference, American Electroplaters and Surface Finishers Society, (1992) pp. 1-10

17. S. Chen, C. Kang, J. Wang, C. Liu, and K. Sun, Synthesis of Anodizing Composite Films Containing Superfine $\mathrm{Al}_{2} \mathrm{O}_{3}$ and PTFE Particles on Al Alloys, Appl. Surf. Sci., 2010, 256, p 6518-6525

18. W. Zhang, D. Zhang, Y. Le, L. Li, and O. Bin, Fabrication of Surface Self-lubricating Composites of Aluminum Alloy, Appl. Surf. Sci., 2008, 255, p 2671-2674

19. P. Kwolek, P. Górecka, A. Oblój, U. Kwolek, M. Dychtoń, K. Drajewicz, and J. Sieniawski, The Teflon Impregnation of Anodic Coating Onto Aluminium Substrate, Chemik, 2016, 70, p 365-368

20. Anselm Kuhn, PTFE Coating vs. Impregnation, Met. Finish., 2004, 102, p 12-17

21. L. Hao and R. Cheng, Sealing Processes of Anodic Coatings-Past, Present, and Future, Met. Finish., 2000, 98, p 8-18

22. S.J. Bull and E.G. Berasetegui, An Overview of the Potential of Quantitative Coating Adhesion Measurement by Scratch Testing, Tribol. Int., 2006, 39, p 99-114 